\title{
Knowledge associated with the support provided by couples to climacteric women in Mexican population
}

\begin{abstract}
The support that couples provide to women during the climacteric is essential for a less complex transition. One of the factors that could influence is the knowledge they have about the physical, psychological and social manifestations, hence the importance of this study, from which it is based on a proposal about nursing educational intervention programs. Objective of this study: To analyze the correlation between the knowledge and support provided by couples of women during the climacteric. Methodology: Quantitative, correlational and transversal research. The sample includes 100 participants, a couple of women aged 45 to 59 years old. The instrument was a questionnaire validated by experts, where a reliability of .758 was obtained.

The application was by google.doc (https://goo.gl/forms/xJykXtbxiFGNS5yq2). The results are: the level of knowledge among the couples of women was regular to deficient $82 \%$; The level of support was $49 \%$ among deficient and regular. Significant statistical correlation was found $(\mathrm{p} \geq 0.05)$ with Chi2 test. Conclusion The level of knowledge is deficient in the couples of women during climacteric and only half of it, provide support, which supports nursing educational interventions
\end{abstract}

Keywords: (MeSH) climacteric social support, women, couples
Volume 6 Issue 3 - 2019

\section{María Dolores Martínez Garduño, Danelia \\ Gómez Torres, Patricia Cruz Bello, Laura \\ Montserrath Espinoza Zenil}

School of Nursing and Obstetrics, Autonomous Mexico State University, Mexico

Correspondence: María Dolores Martínez Garduño, School of Nursing and Obstetrics, Autonomous Mexico State University, Mexico,Email dolmaa@gmail.com

Received: June 12, 2019 | Published: July 05, 2019

\section{Introduction}

The support that is expressed in relationships is vital because it is the fundamental within marital relationships. Currently, one of the main reasons why relationships begin to crumble is the lack of support and communication within the couple, which generates a lack of knowledge of their own needs; that is the reason why it is important to know the needs and the support couples are having. It is also important to know the person with whom life is shared and thus strengthen relationships. A relationship lasts when the results of it are charitable and satisfy the individuals. The obtained rewards from a relationship are contrasted to the results that have been obtained in it.

When individuals influence on the level of their partners' achieved goals, a mutual dependence is developed, which is defined as the level of an individual relies on the relationship to fulfill the important needs of it; or the degree in which the couple counts on the other one only to satisfy important results. ${ }^{1}$

The transition of the climacteric is a very variable cultural phenomenon and the complexity of the psychosocial and biological factors of aging, they produce a wide variability of symptoms, as well as the consequences for health in long term. The climacteric concept incorporates perimenopause, extending for a longer variable period before and after perimenopause; the term natural menopause is defined as the permanent cessation of menstruation caused by the loss of ovarian follicular activity. It is recognized that natural menopause has occurred after 12 consecutive months of amenorrhea, because there is no other obvious pathology or physiological cause. Menopause occurs with the final menstrual period that is known with certainty only in retrospect one year after the event. ${ }^{2}$
In Latin America, in general, menopause occurs between 43 and 53 years old, which is below that developed countries. ${ }^{3}$ The effects of menopause for women are of vital importance as it is the cessation of reproductive life and regarding the causes and symptomatology of this stage, it can be noted that there is still a lack of understanding in this subject by women. As an example they do not recognize some prevalent symptoms of this period such as anxiety, but they relate it to stress of daily life and they tend to link other symptoms such as halitosis with the climacteric, this reflects a predisposition to associate all the negative manifestations of the body with the climacteric stage.

At climacteric stage when changes in genital structure occur, they cause sexuality problems influenced by mood swings and self-esteem as a consequence of life quality, hence the importance of the support of the couple. ${ }^{4}$

The support that couples provide to women during the climacteric is essential to make this stage less difficult for many women. One of the factors that could influence is the knowledge they have about the physical, psychological and social manifestations, therefore the importance of this study, from which it is intended to propose educational intervention programs, It also favors the expression of their feelings of love, affection and understanding; if possible, financial support that involves attention to her health.

Every day, more women live longer, currently about $15 \%$ of the women population is between 45 and 59 years old, ${ }^{5}$ which this stage has become a challenge for health systems, due to the physical and psychological manifestations related to the estrogenic decrease. ${ }^{6}$ So alternatives should be given in order to achieve a transition towards healthier elderly people, among the highlighted nursing roles are the design and implementation of programs about health promotion 
and prevention aimed to women and involve their partners, as the main element of social support. In the quest for research on men's knowledge of climacteric and more, the support for the couple, no data was found. The objective of this study is to analyze the correlation between the knowledge and support offered by couples to women during the climacteric.

\section{Material and methods}

This investigation has a quantitative, correlational and transversal methodological approach. To determine the universe of study, the figures from the National Institute of Statistics and Geography in Mexico in 2015 were considered, where 35,930 women aged 45 to 59 are reported in the Municipality of Toluca, to relate the number of couples of women in this age The sample was calculated with the Epinfo program, ${ }^{7}$ with a confidence level of $95 \%$ and maximum error of $7 \%$, with a total of 100 participants. The participants were male partners (husbands or concubines), who had at least 5 years living together as a couple of women between 45 and 59 years old (in order to have been in the transition moments); that they know how to read and write, so that it is not a reason for lack of information search, in addition to handling email and / or WhatsApp.

\section{Instrument}

For the construction of the instrument were considered the knowledge in section six dimensions: age understood, manifestations, pharmacological, alternative and care treatments; as for the support, the items were formulated in two dimensions: emotional (conflict, communication, accompaniment and affection samples) and instrumental (economic support). The instrument was validated by three experts (Professor of the Autonomous University of the State of Mexico, President of the Association for the Study of the climacteric in the State of Mexico and a Psychology Autonomous University of the State of Mexico), in three rounds; from which it is integrated as follows: it contains two sections, the first corresponds to sociodemographic data and the second to the questions that add up to 34; from question 1 to question 23 correspond to knowledge and from question 23 to question 33 correspond to the support they provide. The answer options are: Yes, no, I do not know. A score is assigned of 0 (no and I do not know) and 1 (yes) corresponding to positive or negative results. The scores are interpreted as follows: Knowledge: 12-16=high, 6-11= regular and 0-5=low; Social support 12-16=high, 6-11=regular and 0-5=law, Process. The application of the instrument was made by email or WhatsApp (link: https://goo.gl/forms/ xJykXtbxiFGNS5yq2). Couples of women were contacted aged 45 to 59 years, they were informed of the purpose of the investigation to proceed with the informed consent, and they were given a guarantee of confidentiality. After acceptance, a directory with emails and/or cell phone number was prepared.

Once the surveys were concluded, data were collected in the SPSS Vs 22 program and descriptive statistics of central tendency and Chi2 correlation were applied. The reliability obtained from the instrument with Kuder Richardson was .758, which is considered acceptable. This study is registered in the Autonomous University of the State of Mexico with number 4452/2017SF and meets the criteria of confidentiality according to the Declaration of Helsinki, General Health Law and the Regulation of the General Health Law in Mexico.

\section{Results}

The age of the participating men is located at $\mu=51.8 \pm 3.56$, with a minimum age of 39 and a maximum age of 70 . The highest percentage is between 39 and 55 years, mostly married (75\%); less than half with undergraduate and graduate studies (40\%); in occupation $57 \%$ are employees (Table 1). The level of knowledge of deficient women couples, with a total of $65 \%$ and $17 \%$ regular and $18 \%$ high. Regarding the knowledge of couples of women who are in climacteric in the city of Toluca, $51 \%$ identified in concept of menopause and $65 \%$ the concept of climacteric; $78 \%$ acknowledge that early menopause appears before age $40 ; 48 \%$ identified that with the tubal ligation does not start menopause; $57 \%$ are correct in confirming that menopause is not at 40 years of age; $79 \%$ know that ovaries reduce the production of hormones during this stage.

Table I Sociodemographic data of couples of women who are in climacteric

\begin{tabular}{|c|c|c|}
\hline \multirow[b]{3}{*}{ Age } & \multicolumn{2}{|l|}{$n=100$} \\
\hline & Freq. & $\%$ \\
\hline & & \\
\hline $39-45$ & 18 & 18.0 \\
\hline $46-50$ & 28 & 28.0 \\
\hline $5 I-55$ & 31 & 31.0 \\
\hline $56-60$ & 17 & 17.0 \\
\hline $61-65$ & 4 & 4.0 \\
\hline $66-70$ & 2 & 2.0 \\
\hline \multicolumn{3}{|l|}{ Civil status } \\
\hline Married & 75 & 75.0 \\
\hline Single with partner & 17 & 17.0 \\
\hline Divorced & 8 & 8.0 \\
\hline \multicolumn{3}{|l|}{ Scholarship } \\
\hline Primary & 7 & 7.0 \\
\hline High school & 18 & 18.0 \\
\hline Medium superior level & 22 & 22.0 \\
\hline Technical & 13 & 13.0 \\
\hline Bachelor's degree & 27 & 27.0 \\
\hline Master's degree & 11 & 11.0 \\
\hline Doctor degree & 2 & 2.0 \\
\hline \multicolumn{3}{|l|}{ Occupation } \\
\hline Employee & 57 & 57.0 \\
\hline Independent work & 25 & 25.0 \\
\hline Independent professional & 9 & 9.0 \\
\hline Retired & 8 & 8.0 \\
\hline Unemployed & 1 & 1.0 \\
\hline
\end{tabular}

The $62 \%$ asseverate that hot flashes and sweats are due to women's nervousness; contrary to this, $63 \%$ identify the hot flushes as a cause of insomnia; $74 \%$ relate vaginal dryness with climacteric; $79 \%$ state 
that all women have the same symptoms during the climacteric. $48 \%$ of couples participating in this study believe that when a woman presents discomfort during sexual intercourse, they should be avoided; $76 \%$ consider that having sex during menopause harms the health of women; only $45 \%$ say that women enjoy sex more when the risk of pregnancy disappears; $51 \%$ state that due to the loss of estrogen, the elasticity of the vagina is lost; $63 \%$ state that women experience the disappearance of menstruation as a release; $74 \%$ say that the relationship between women and their partners with society influences the way they accept menopause, $44 \%$ say that some women think their lives end when children become independent; $37 \%$ think that when children leave home and the arrival of grandchildren, they do not influence the experience of menopause; $81 \%$ say that most women feel misunderstood after menopause.

With respect to the knowledge of the couples of women about the treatment during the climacteric, it was found that $42 \%$ know the benefits of hormonal treatment to reduce cardiovascular diseases and osteoporosis; likewise, $90 \%$ affirm that they must go to periodic medical check-ups. Regarding the knowledge of the couples of women about the care during the climacteric, it was found that $87 \%$ said that physical exercise is important during this stage and only $49 \%$ have been informed about the climacteric. According to the scores determined, it is observed that the level of support provided by couples of women in the climacteric stage is good only in 51\% (Table 2).

Table 2 Level of support of couples of women who are in climacteric

\begin{tabular}{lll}
\hline & $\mathrm{n}=100$ & \\
Level & Freq. & $\%$ \\
\hline High & 51 & 51 \\
Regular & 39 & 39 \\
Low & 10 & 10 \\
\hline
\end{tabular}

When the couple has hot flashes, $69 \%$ support the woman to feel more comfortable physically, 58\% have good communication with their partner because they talk about their physical and emotional manifestations derived from the climacteric, $85 \%$ of men think that women are less physical and sexually attractive and $15 \%$ say it is the opposite, $77 \%$ of men express love and understanding towards their partner in this climacteric stage and 23\% affirm the opposite; $84 \%$ of men seek sexual intercourse for both at this stage; $85 \%$ support their partner to have a positive attitude towards themselves, $54 \%$ of the participants propose the use of gels to lubricate the vagina and promote sexual relations. $71 \%$ provide financial support for medical consultations derived from the climacteric and $73 \%$ provide support for the hormones replacement therapy. The hypothesis is verified, a statistically significant correlation was found between knowledge and support of the couple (Table 3).

Table 3 Correlations between support, knowledge, scholarship and occupation

\begin{tabular}{lllll}
\hline & I & 2 & 3 & 4 \\
\hline I. Support of the couple & - & $.339 * *$ & $.203^{*}$ & .177 \\
2. Knowledge & - & $.327 * *$ & .115 \\
3. Scholarship & & - & .078 \\
4. Occupation & & & - \\
\hline
\end{tabular}

Statistical significance $*_{p} \leq 0.05 * * p \leq 0.01$

\section{Discussion}

Women's health is influenced by biological, environmental, economic and social diverse factors and it is the couple's knowledge and support, which are addressed in this study, where the couple represents an essential support in coping with this stage, as there are shown in different studies, due to women in this stage are susceptible to psychological distress, especially anxiety and depression. ${ }^{8}$

The level of knowledge found in this research in couples of women during the climacteric, regarding the concept is deficient, less than a half does not identify the concept of menopause but the climacteric does; these data matches with a study conducted with men and women who only $48 \%$ identified that the climacteric is the period of transition from reproductive to non-reproductive life, in the same way a minimum percentage identified the age of appearance. ${ }^{9}$ Another study, even though it was carried out on women, was also observed that the knowledge they have is scarce; ${ }^{10}$ situation that should be attended to for both sexes. Something that most are cleared, is that early menopause is when it appears before 40 years. In this sense, early menopause has increased according to a study carried out in Korean women and this has been related to women who have lower income, lower educational level, married, unemployed, who reside in urban areas, smokers and those with obesity. ${ }^{11}$

The majority of the participants in the study, identify that the vasomotor symptoms are not due to the nervousness of women, but if they establish that they cause insomnia, as mentioned in various studies having being presented in $40-60 \%$ of women agreed to results of other studies ${ }^{12,13}$ and is one of the main health problems in peri and postmenopausal women. ${ }^{14}$ The severity of menopausal symptoms is influenced by biopsychosocial factors, the beginnings of symptoms is also affected by the well being, professional status and lifestyle, psychological and somatic symptoms as well as sexual and vasomotor symptoms related to the climacteric process they are most likely to be associated with psychosocial factors. ${ }^{15}$ Another manifestation of great importance is vaginal dryness, due to vulvovaginal atrophy, given by the estrogenic decrease, which is often accompanied by pain, irritation or itching, pain during sexual intercourse and bleeding later, a condition that affects the $25-50 \%$ of postmenopausal women. ${ }^{16}$ In this sense, they obtained mostly affirmative responses to this manifestation, which would be greater understanding of their partners more expected, however, the answer to this situation is to avoid relationships, although there are alternatives to treat the vaginal dryness, such as vaginal lubricants and estrogen treatment. ${ }^{17}$

The majority identify as harmless to women's health keeping sexual relationships during menopause, however less than half mentioned that women enjoy sex more when the risk of pregnancy disappears, similar studies confirm that women live menopause as a release and without fear of pregnancy. ${ }^{17,18}$

One of the most prominent changes during this period is the composition of home; stage in which the so-called empty nest syndrome appears, to period in which the adult child no longer lives at home, a stage in which it would be assumed that their function of responsibilities as a mother has ended, contrary to this empty nest, ${ }^{19}$ the revolving door syndrome appears, when the adult children return with their family and see the woman as support in the care of the family and possibly, the couples of the women in the climacteric see the continuing care of the grandchildren as another function. They also consider that women feel more misunderstood in this stage of life, which is confirmed by other studies in which women manifest communication problems with their partner. ${ }^{20}$ 
Regarding the treatment of Hormone Replacement Therapy (HRT) during menopause, very few know its benefits to prevent or delay cardiovascular diseases. Cardiovascular disease is the main cause of morbidity and mortality in postmenopausal women and it has been shown that hormone therapy can have cardioprotective effects, if it starts around the time of menopause. As for osteoporosis, also hormone therapy, has benefits for connective tissue, skin, joints and intervertebral discs. In addition, it can reduce the risk of colon cancer. $^{21}$

The HRT also favors the decrease of physical, psychological and sexual manifestations, where the main indication of HRT are vasomotor symptoms combined with the decrease in anxiety as shown in a study, where it is described that combined HRT with kava decreases anxiety. ${ }^{22}$ Regarding sexuality, a systematic review study shows a positive effect of HRT to improve dyspareunia, vaginal resection and sexual function in general; both in excitement, orgasm and satisfaction..$^{23}$

Couples of women in the climacteric, recognize the importance of exercise, an important aspect because when performing exercise before and during this stage, the reduction of climacteric symptoms is favored, hence the physical exercise has acquired increasing importance within the therapy in the climacteric, which is why it has been shown that it modifies risk factors as important as cardiovascular diseases and the development of osteoporosis with posterior fractures. ${ }^{24}$ Greater physical activity within four domains of life, sport, active life, home and work were associated with a greater peak force of the femoral neck. ${ }^{25}$ However, globally, knowledge is deficient, they correctly identify that women must go periodically to medical examinations as described in NOM 035 SSA2-2012 $2^{26}$ this norm, where the promotion actions are emphasized and prevention for better health.

Results of this study show only a little more than half facilitate physical well-being during vasomotor manifestations, which in some way could be related to the distance they seek during these moments, when women feel more vulnerable and in need of understanding ${ }^{27}$ It is striking that women are less attractive, and although couples say that this stage does not change their sexual interest in them, this aspect should be studied in greater depth. Supporting a positive body image can help middle-aged women maintain sexual satisfaction with aging, whereas men consider it less attractive from the climacteric. ${ }^{28}$ It is important to highlight that postmenopausal has been described as a risk factor on conjugal dysfunction, inadequate communication and lack of affection were the functions that have been most strongly associated with conjugal dysfunction; some studies that have been conducted on women in the climacteric have determined an alteration in the family and conjugal environment, the most frequent complaints being dissatisfaction due to lack of family support and little communication among all its members. Regarding the couple's relationship, the area that has been studied with greater emphasis is the sexual sphere, reporting in 39\% dissatisfaction; $57 \%$ had difficulty reaching orgasm; and also highlight the few manifestations of affection with their partners and the quality of time dedicated to women. ${ }^{29}$

Having a good communication during this period would be positive for the woman and for the relationship itself, because in some studies it has been shown that effective communication is relevant to the stability of a couple, and that communication is directly related with marital satisfaction and is a key element of positive long-term relationships. ${ }^{30}$ Undoubtedly there are changes in the appearance of women in climacteric, especially weight gain and changes in breasts, it is described that the body image of women impacted their sexual satisfaction; feeling attractive is important for sexual satisfaction in middle-aged women.

Finally, it is undeniable medicalization for the care of women who have severe vasomotor symptoms or other related that affect their sexual functionality, however it is necessary to recognize the importance of HRT, as a preventive measure of osteoporosis, there lies the importance that can have the support provided by couples of women in menopause, to live a fuller climacteric; in this sense, couples claim to provide instrumental (economic) support to women for consultation and acquisition of hormone replacement therapy, a little more than half proposes the use of gels. One of the factors that determine family conflicts are the economy up to $61 \%$ (28) element, which must be considered, especially if there is an economic dependence on women.

\section{Conclusion}

The men's level of knowledge about the climacteric is deficient in terms of the emotional support provided by men to their partners, it was determined that only half of them helps women making them feel more comfortable physically, that men have a good communication when talking about physical and emotional manifestations derived from the climacteric. Statistically significant correlation was found among the knowledge of women's partners during the climacteric and the support they provide.

According to the results and limitations of the study, the following is suggested:

Implement an educational intervention program to improve the knowledge that men have about the support they provide to women during the climateric. Supplement this study with qualitative research, which can provide a broader view of the perception of couples, related to the support they provide and the perception of women receiving support during this period.

\section{Acknowledgments}

None.

\section{Conflict of interest}

The authors declare that there is no conflict of interest.

\section{References}

1. Torres T, Ojeda A. Commitment and Stability in the Couple: Definition and Dimensions within the Mexican Population Iberoamerican Psychology. 2009; 17(1):38-47.

2. Utian WH. The International Menopause menopause-related terminology definitions. Climacteric. 1999;2(4):284-286.

3. Santos T, Pereira S, Santos R. Intensity of climacteric symptoms in postmenopausal women. Revista Rede de Enfermagem do Nordeste. 2016;17(2):225-232.

4. Thomas HN, Neal-Perry GS, Hess R. Female Sexual Function at Midlife and Beyond. Obstet Gynecol Clin North Am. 2018;45(4):709-722.

5. National Institute of Statistics and Geography INEGI. Count me population by entity. 2015 . 
6. Kravitz HM, Kazlauskaite R, Joffe H. Sleep, Health, and Metabolism in Midlife Women and Menopause. Obstetrics and Gynecology Clinics of North America. 2018;45(4):679-694.

7. Centers for Disease Control and Prevention. 2017.

8. Leventhal AJ, Dennerstein L, Fugate WN, et al. Role of stressful life events and menopausal stage in wellbeing and health, Expert Review of Neurotherapeutics. 2007;7(11 suppl 1):S93-S113.

9. Leiva DV, Arguedas MC, Hidalgo CM, et al. Conocimiento de las personas adultas sobre el climaterio, andropausia y la sexualidad. Rev Ciencias Sociales. 2013;140:163-173.

10. Martínez GMD. Escobar ChTJ, Soriano RC. Autocuidado de mujeres en etapa de menopausia en Toluca, México. Escola Anna Nery Revista de Enfermagem. 2008;12(1):63-67.

11. Lima YM, Jeonga $\mathrm{K}$, Leea SR, et al. Association between premature ovarian insufficiency, early menopause. Maturitas. 2019;121:22-27.

12. Joffe H, Massler A, Sharkey K. Evaluation and management of sleep disturbance during the menopause transition. Semin Reprod Med. 2010;28(5):404-421.

13. Polo KP. Sleep problems in midlife and beyond. Maturitas. 2011;68:224-232.

14. van Dijk G. Kavousi M, Troup J, Franco O. Health issues for menopausal women: The top 11conditions have common solutions. Maturitas. 2015;80:24-30.

15. Burn K, Dennerstein L, Browning C, et al. Patterns of social engagement in the transition to later life. Maturitas. 2016;88:90-95.

16. Vale F, Rezende C, Raciclan A, et al. Efficacy and safety of a nonhormonal intravaginal moisturizer for the treatment of vaginal dryness in postmenopausal women with sexual dysfunction. European Journal of Obstetrics \& Gynecology and Reproductive Biology. 2019;234:92-95.

17. Hvas, L. Positive aspects of menopause. Maturitas. 2001;39(1):11-17.

18. Manzo. E. Sexuality and affectivity in the climacteric. Midwife Profession 2002;3(8);13-20

19. Marván GML. Climacteric Experience from a Psychosocial Perspective Health and Administration. 2017;4:27-43.
20. Pavón N, Dickinson M, González C. El climaterio como factor de riesgo en casos de disfunción conyugal. Atención familia. 2014;21(2):35-38.

21. Martín S, Benedí J. Hormone Replacement Therapy, focus on menopause. Professional Pharmacy. 2009;23(2).

22. De Leo V, la Marca A, Morgante G, et al. Evaluation of combining kava extract with hormone replacement therapy in the treatment of postmenopausal anxiety. Maturitas. 2001;25;39(2):185-188.

23. Pitkin J. Sexuality and the menopause. Best Practice \& Research Clinical Obstetrics \& Gynaecology. 2009;23(1):2009:33-52.

24. Ramírez R, Triana HR. Effect in the quality of life related to health (QLRH) of program therapeutic activity in water, in a group of persons with year old non instituionalized. Cali, 2006. Rev Iberoam Fisioter Kinesol. 2007;10:24-37.

25. Mori T, Ishii S, Greendale GA, et al. Physical activity as determinant of femoral neck strength relative to load in adult women: findings from the hipstrength across the menopause transition study. Osteoporosis International. 2014;25(1):265-272.

26. Diario Oficial de la Federación (DOF). NORMA Official Mexican NOM-035-SSA2-2012, For the prevention and control of diseases in the perimenopause and postmenopause of women. Criteria to provide medical care. 2013.

27. Simpson, EEA. Stress and Coping in the Menopause. Stress: Concepts, Cognition, Emotion, and Behavior. 2016;1:451-455.

28. Pavón, N. Dickinson, M. González, C. El climaterio como factor de riesgo en casos de disfunción conyugal Atención familiar. Atención Familiar. 2014;21(2):35-38.

29. Thomas, HN, Hamm M, Borrero S, et al. Body Image, Attractiveness, and Sexual Satisfaction Among Midlife Women: A Qualitative Study. Journal of Women's Health. 2018;28(1):100-106.

30. Schmidt CD, Luquet W, Gehlert NC. Evaluating the Impact of the "Getting The Love You Want" Couples Workshop on Relational Satisfaction and Communication Patterns. Journal of Couple \& Relationship Therapy. 2015;15(1):1-18. 